\title{
Multimodel Modeling and Predictive Control for Direct-Drive Wind Turbine with Permanent Magnet Synchronous Generator
}

\author{
Lei Wang, Tao Shen, and Chen Chen \\ School of Automation, Chongqing University, Chongqing 40044, China \\ Correspondence should be addressed to Lei Wang; leiwang08@cqu.edu.cn
}

Received 8 July 2014; Accepted 25 August 2014

Academic Editor: Zheng-Guang Wu

Copyright ( 2015 Lei Wang et al. This is an open access article distributed under the Creative Commons Attribution License, which permits unrestricted use, distribution, and reproduction in any medium, provided the original work is properly cited.

\begin{abstract}
The safety and reliability of the wind turbines wholly depend on the completeness and reliability of the control system which is an important problem for the validity of the wind energy conversion systems (WECSs). A method based on multimodel modeling and predictive control is proposed for the optimal operation of direct-drive wind turbine with permanent magnet synchronous generator in this paper. In this strategy, wind turbine with direct-drive permanent magnet synchronous generator is modeled and a backpropagation artificial neural network is designed to estimate the wind speed loaded into the turbine model in real time through the estimated turbine shaft speed and mechanical power. The nonlinear wind turbine system is presented by multiple linear models. The desired trajectory of the nonlinear system is decomposed to be suitable for the reference trajectory of multiple models that are presented by the linear models of the nonlinear system, which simplifies the nonlinear optimization problems and decreases the calculation difficulty. Then a multivariable control strategy based on model predictive control techniques for the control of variablespeed variable-pitch wind turbines is proposed. Finally, simulation results are given to illustrate the effectiveness of the proposed strategy, and the conclusion that multiple model predictive controller (MMPC) has better control performance than the PI control method is obtained.
\end{abstract}

\section{Introduction}

Power outputs of variable-speed variable-pitch wind turbine in different wind speeds are generally illustrated by their power curves which show the steady relationship between wind speed and electrical power. The operation states of the wind power generation include three models [1]:

model 1 -operating at variable speed/optimum tipspeed ratio: $u_{C} \leq v \leq u_{B}$,

model 2-operating at constant speed/variable tipspeed ratio: $u_{B} \leq v \leq u_{R}$,

model 3-operating at variable speed/constant power: $u_{R} \leq v \leq u_{F}$,

which are illustrated in Figure 1 , where $u_{C}$ represents cut-in wind speed, $u_{B}$ represents the wind speed when the generator comes to the maximum rotational speed, $u_{R}$ is the rated wind speed of the wind turbine, and $u_{F}$ is the furling wind speed at which the turbines need to shut down for protection.

The safety and reliability of the WECSs wholly depend on the completeness and reliability of the control system which is an important problem for the validity of the wind turbine system even the safe and reliable operation of the wind power plant for a long time [2]. Many controller research methods including linear ones and nonlinear ones have been applied to the operation control of the WECSs. Due to a good deal of calculation of the nonlinear controller, linear controller remains the mainstream in the wind turbines control. There has existed controlling methods for the WECSs operation, the design of PI controller [3], adaptive controller [1, 4, 5], Gain scheduling controller $[6,7]$, robust controller [8], and model predictive controller $[9,10]$. However, most of the controllers reported ignore the multiparametric nature of the problem. The multivariable controller that can work for controlling variable-speed variable-pitch wind turbines in the partial and full load regions can be found in $[9,11,12]$. 


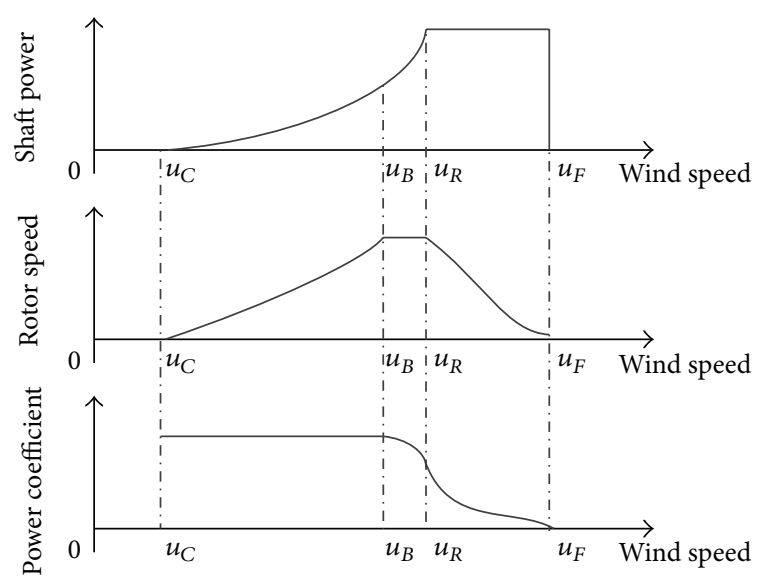

FIGURE 1: Variable speed operation division of wind turbines.

Model predictive control (MPC) has been developed as a new type of computer control algorithm in recent years [13-15]. It has a better control effect with such control strategies as multistep predictive, rolling optimization and feedback correction. Therefore, MPC, it is suitable to control complex industrial processes which have difficulties in building accurate mathematical models. Multiple model control method based on plant models is a common method in dealing with complex nonlinear systems. Generally, multiple model control method approaches the dynamic features of the controlled object by using multiple models. Then with multiple controller based on their corresponding multiple models, it controls the controlled objects in different industrial conditions [16-19].

In this paper, a new kind of modeling method of directdrive wind turbine with permanent magnet synchronous generator (PMSG) is proposed and a new control strategy based on MMPC is described for controlling variable-speed variable-pitch wind turbines in both partial and full load regions. The main contributions of this paper are the consideration of the multiparametric nature of the system and the design of PMSG model for MMPC to obtain better performance in the whole operating regimes of the WECS.

The remainder of the paper is organized as follows: in Section 2, the used wind turbine benchmark model is introduced. The reference/baseline control system of the wind turbine benchmark based on multiple model predictive control approaches is presented in Section 3. Section 4 presents the simulation results with some comments and discussion. Finally, conclusions are drawn in Section 5.

\section{System Modeling}

System of direct-drive wind turbine mainly consists of the blades, the wheel hub, the nacelle, the variable pitch structure, the yaw system, the tower, the synchronous generator, the converters and the whole control system, and so forth, among which the full power converter includes the rectifier at the side of generator and the inverter at the grid side, as shown in Figure 2 [20].
The aerodynamic torque extracted by the wind turbine from the passing wind is given by

$$
T_{m}=\frac{0.5 \rho \pi R^{5} \omega_{t}^{2} C_{p}(\lambda, \beta)}{\lambda^{3}},
$$

where $C_{p}(\lambda, \beta) \leq C_{p, \text { Betz }} \approx 0.56$ is the power coefficient of the wind turbine; $\beta$ is the pitch angle; $\omega_{t}$ is the turbine shaft speed; the tip speed ratio $\lambda$ is defined as the ratio between the linear blade tip speed and wind speed given as follows:

$$
\lambda=\frac{\omega_{t} R}{v} .
$$

The power coefficient for a specific wind turbine design given by (3) is used here:

$$
\begin{gathered}
C_{p}(\lambda, \beta)=0.5173\left(\frac{116}{\lambda_{1}}-0.4 \beta-5\right) e^{-21 / \lambda_{1}}+0.0068 \lambda, \\
\frac{1}{\lambda_{1}}=\frac{1}{\lambda+0.08 \beta}-\frac{0.035}{\beta^{3}+1} .
\end{gathered}
$$

The pitch actuator is modelled by a first order equivalent dynamic system with the saturation in the amplitude and derivative of the pitch, as seen in the following:

$$
\frac{d \beta}{d t}=-\frac{1}{\tau} \beta+\frac{1}{\tau} \beta^{*}
$$

In this paper, the linearization of transmitting torque equation leads to the following:

$$
\begin{gathered}
\delta T_{m}=H_{\omega}\left(\bar{\omega}_{t}, \bar{v}, \bar{\beta}\right) \delta \omega_{t}+H_{v}\left(\overline{\omega_{t}}, \bar{v}, \bar{\beta}\right) \delta v \\
+H_{\beta}\left(\overline{\omega_{t}}, \bar{v}, \bar{\beta}\right) \delta \beta, \\
H_{\omega}=\left.\frac{\partial T_{m}}{\partial \omega_{t}}\right|_{\left(\bar{\omega}_{t}, \bar{v}, \bar{\beta}\right)}, \quad H_{v}=\left.\frac{\partial T_{m}}{\partial v}\right|_{\left(\bar{\omega}_{t}, \bar{v}, \bar{\beta}\right)}, \\
H_{\beta}=\left.\frac{\partial T_{m}}{\partial \beta}\right|_{\left(\bar{\omega}_{t}, \bar{v}, \bar{\beta}\right)} .
\end{gathered}
$$

In most cases, for a direct-drive wind turbine system, the dynamic equations of a PMSG without saliency can be written in a synchronously rotating $d-q$ reference frame as follows:

$$
\begin{aligned}
& u_{d}=R i_{d}+L_{d} \dot{i_{d}}-\Phi_{q} \omega_{s}, \\
& u_{q}=R i_{q}+L_{q} \dot{i_{q}}-\Phi_{d} \omega_{s},
\end{aligned}
$$

where $u_{d}[\mathrm{~V}]$ and $u_{q}[\mathrm{~V}]$ are the $q$-axis and $d$-axis stator terminal voltages, respectively; $i_{d}[\mathrm{~A}]$ and $i_{q}[\mathrm{~A}]$ are the $q$ axis and $d$-axis stator currents, respectively; $R[\mathrm{~V} / \mathrm{A}]$ is the stator resistance; $\omega_{s}$ is the electrical angular velocity of the 


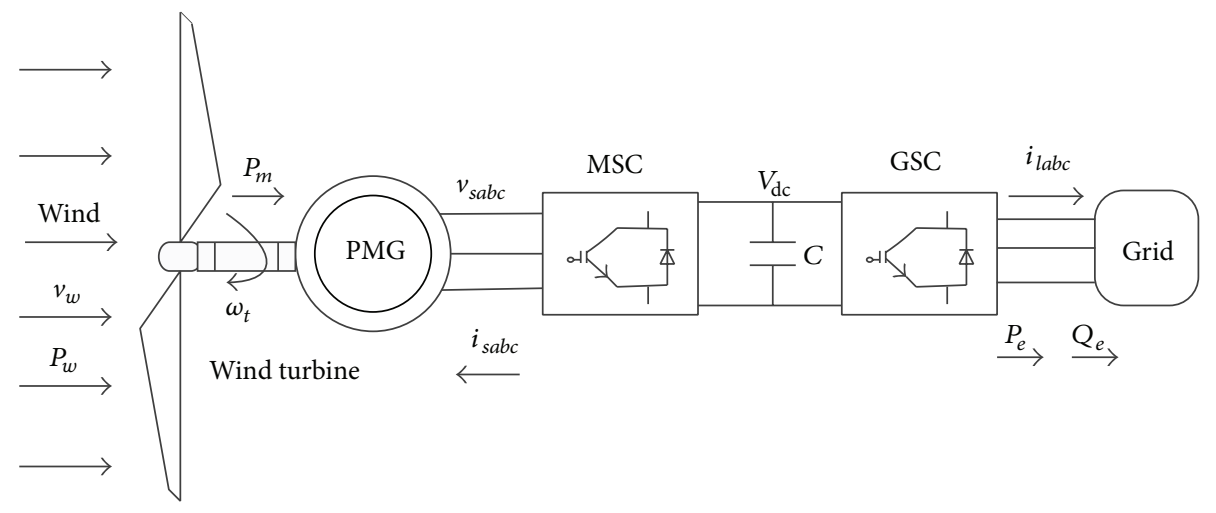

FIGURE 2: The model of direct-drive wind turbine.

rotor $\left(\omega_{s}=p \omega_{t}, p\right.$ is pole pairs); and $\Phi_{q}$ and $\Phi_{d}$ are the $q$ axis and $d$-axis flux linkages of the PMSG, respectively, given by the following:

$$
\begin{gathered}
\Phi_{q}=L_{q} i_{q}, \\
\Phi_{d}=L_{d} i_{d}+\Phi_{m},
\end{gathered}
$$

where $\Phi_{m}$ is the permanent magnet flux linkage; $L_{q}$ and $L_{d}$ are the $q$-axis and $d$-axis inductances of the PMSG, respectively.

The dynamics of the mechanical wind turbine system are given by the following:

$$
J \frac{d \omega_{t}}{d t}=T_{m}-T_{e}-D \omega_{t}
$$

where $J$ is the total inertia constant of the wind turbine; $D$ is the damping coefficient; and $T_{e}$ is the electrical torque of the PMSG.

For the design of turbine controller, it is important to use simple models to capture the relevant dynamics of the system. Fortunately, the dynamics of the electrical subsystem are much faster than the turbine dynamics and simple models can be used to represent the electrical dynamics. In this paper, a first-order model, given in (9), is used

$$
\begin{gathered}
\frac{d T_{e}}{d t}=-\frac{1}{\tau_{e}} T_{e}+\frac{1}{\tau_{e}} T_{e}^{*}, \\
P_{\mathrm{PMSG}}=T_{e} \omega_{s} \eta,
\end{gathered}
$$

where $T_{e}, \tau_{e}$, and $\eta$ are the generator torque, time constant, and efficiency, respectively [9].

Therefore, the PMSG model connected to the power grid can be expressed as follows:

$$
\begin{gathered}
\dot{x}(t)=\Psi x(t)+\Gamma u(t)+\Upsilon \delta v(t), \\
y(t)=C x(t),
\end{gathered}
$$

that is,

$$
\begin{aligned}
& {\left[\begin{array}{c}
i_{d}^{\prime} \\
i_{q}^{\prime} \\
\delta \omega_{t}^{\prime} \\
\delta T_{m}^{\prime} \\
\delta T_{e}^{\prime} \\
\delta \beta
\end{array}\right]=\left[\begin{array}{cccccc}
-\frac{R}{L_{d}} & \frac{L_{q}}{L_{d}} \omega_{s} & 0 & 0 & 0 & 0 \\
-\frac{R}{L_{q}} & \frac{L_{d}}{L_{q}} \omega_{s} & p \frac{\Phi_{m}}{L_{q}} & 0 & 0 & 0 \\
0 & 0 & -\frac{D}{J} & \frac{1}{J} & -\frac{1}{J} & 0 \\
0 & 0 & H_{\omega} & 0 & 0 & H_{\beta} \\
0 & 0 & 0 & 0 & -\frac{1}{\tau_{e}} & 0 \\
0 & 0 & 0 & 0 & 0 & -\frac{1}{\tau}
\end{array}\right]\left[\begin{array}{c}
i_{d} \\
i_{q} \\
\delta \omega_{t} \\
\delta T_{m} \\
\delta T_{e} \\
\delta \beta
\end{array}\right]} \\
& +\left[\begin{array}{cccc}
\frac{1}{L_{d}} & 0 & 0 & 0 \\
0 & \frac{1}{L_{q}} & 0 & 0 \\
0 & 0 & 0 & 0 \\
0 & 0 & 0 & 0 \\
0 & 0 & \frac{1}{\tau_{e}} & 0 \\
0 & 0 & 0 & \frac{1}{\tau}
\end{array}\right]\left[\begin{array}{c}
u_{d} \\
u_{q} \\
\delta T_{e}^{*} \\
\delta \beta^{*}
\end{array}\right]+\left[\begin{array}{c}
0 \\
0 \\
0 \\
\frac{H_{v}}{J} \\
0 \\
0
\end{array}\right] \delta v, \\
& {\left[\begin{array}{c}
\delta \omega_{t} \\
\delta P_{\mathrm{PMSG}}
\end{array}\right]=\left[\begin{array}{cccccc}
0 & 0 & 1 & 0 & 0 & 0 \\
0 & 0 & \eta p \bar{T}_{e} & 0 & \eta \bar{\omega}_{s} & 0
\end{array}\right]\left[\begin{array}{c}
i_{d} \\
i_{q} \\
\delta \omega_{t} \\
\delta T_{m} \\
\delta T_{e} \\
\delta \beta
\end{array}\right]}
\end{aligned}
$$

where $x(t) \stackrel{\text { def }}{=}\left[\begin{array}{llllll}i_{d} & i_{q} & \delta \omega_{t} & \delta T_{m} & \delta T_{e} & \delta \beta\end{array}\right]^{T} \in R^{6}$ is the state variable of the system, $u(t) \stackrel{\text { def }}{=}\left[\begin{array}{lllll}u_{d} & u_{q} & \delta T_{e}^{*} & \delta \beta^{*}\end{array}\right]^{T} \in R^{4}$ is the control input, and $y(t) \stackrel{\text { def }}{=}\left[\begin{array}{lll}\delta \omega_{t} & \delta P_{\mathrm{PMSG}}\end{array}\right]^{T} \in R^{2}$ is the measured output.

\section{Real-Time Wind Speed Estimation}

If the information of the turbine mechanical power and shaft speed is given, the wind speed can be calculated 


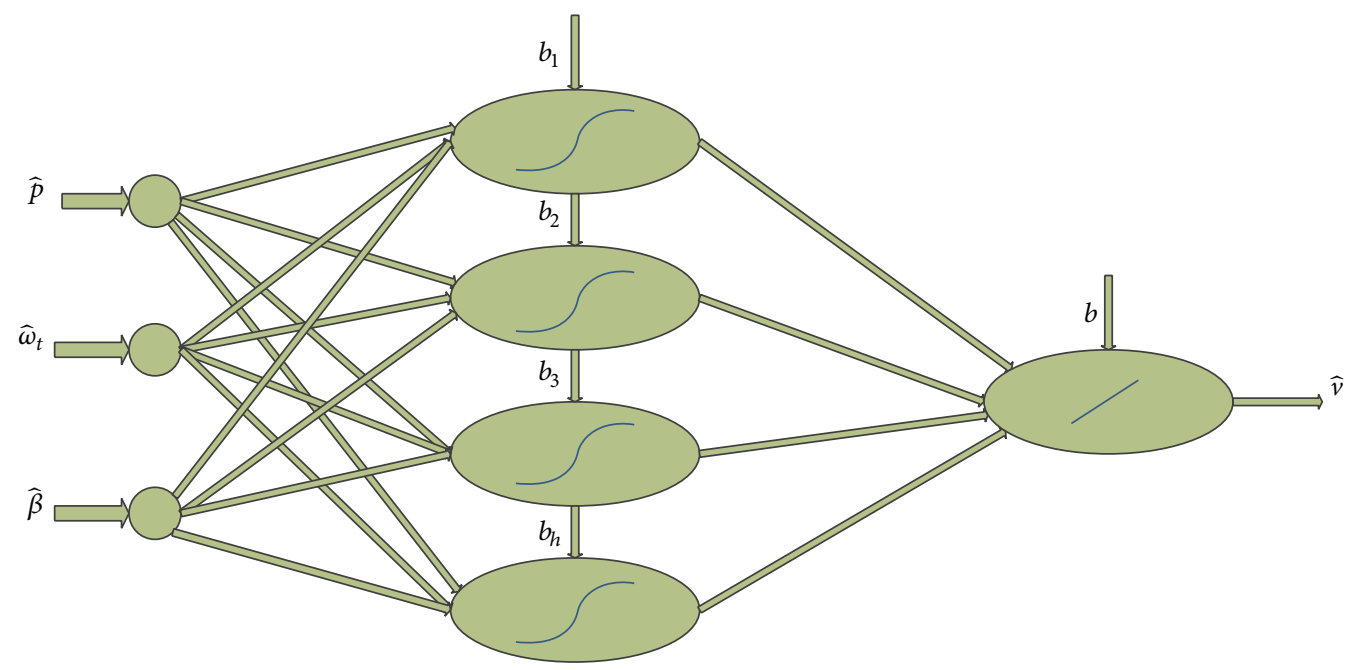

FIgURE 3: BPANN-based wind speed estimation algorithm.

from the nonlinear inverse function of (1). Artificial neural networks (ANNs) are effective tools for nonlinear mapping and are used in this paper for wind speed estimation.

In this paper, a three-layer back propagation artificial neural network (BPANN) is used to estimate wind speed as shown in Figure 3. In the proposed method, $\widehat{P}, \widehat{\omega}_{t}, \widehat{v}$ are the estimated values of $P, \omega_{t}, v$, respectively.

The overall input-output mapping of the BPANN is

$$
\begin{gathered}
\widehat{v}=b+\sum_{j=1}^{h} v_{j} \tan \operatorname{sig}\left(\omega_{1 j} \widehat{p}_{m}+\omega_{2 j} \widehat{\omega}_{t}+\omega_{3 j} \widehat{\beta}+b_{j}\right), \\
\tan \operatorname{sig}(u)=\frac{2}{1+e^{-2 x}}-1,
\end{gathered}
$$

where $h$ is the number of neurons in the hidden layer; $\omega_{1 j}$, $\omega_{2 j}$, and $\omega_{3 j}$ are the weights between the input and the $j$ th neuron in the hidden layer; $v_{j}$ is the weight between the $j$ th neuron in the hidden layer and the output; $b_{j}$ and $b$ are the bias terms of the hidden layer and the output layer, respectively; "tan sig" is the hyperbolic tangent sigmoid transfer function.

The BPANN is trained by using the training dataset until an acceptable error is reached. Then, the parameters of the BPANN are fixed and used for real-time wind speed estimation.

\section{Control Design}

The multiple model control strategy used in this paper is shown in Figure 4. The main ideas are the piecewise linearization of the reference input of nonlinear system and to control each linear model to make it consistent with output of the corresponding multiple model reference trajectory (MMRT). For the reason that the input and output of dynamic process are not the balance points of the system, it cannot get the accurate results by linearizing the nonlinear system. In this paper, a multivariable nonlinear system is approached by multiple linear systems. The reference trajectory is sectionally approached by different linear system. This method is used to control the pitch angle and generator torque of wind turbine to achieve optimal performance. The all operation regions of wind turbine can be divided into $n$ parts, each part of which is described by linear model and uses predictive control to make the output power achieve the desired effect.

The control structure of the whole wind turbine is shown in Figures 5 and 6 . With given rated power and rotational speed, the pitch angle and torque obtained through the multiple model predicative control can make the wind turbine system output the desired power meeting the expected goal.

Take the nonlinear system $\Sigma$ into consideration:

$$
\begin{gathered}
x(k+1)=f(x(k), u(k)), \\
y(k)=g(x(k), u(k)) .
\end{gathered}
$$

For the chosen output state $y=y_{0}$, if the equation could be solved, a balance point $\left(x_{0}, y_{0}, z_{0}\right)$ of the system can be got. If $N$ balance points $\left(x_{i}, y_{i}, z_{i}\right), i=0,1, \ldots, N-1$ are chosen in the output area $Y, N$ linear model $\Sigma_{i}$ of the nonlinear system can be gained at different balance points:

$$
\begin{gathered}
x^{i}(k+1)=A^{i} x^{i}(k)+B_{u}^{i} u(k)+B_{d}^{i} d^{i}(k)-\alpha^{i}, \\
y^{i}(k)=C^{i} x(k)+D_{d}^{i} d^{i}(k)-\gamma^{i},
\end{gathered}
$$

where

$$
\begin{aligned}
& A^{i}=\left.\frac{\partial f}{\partial x}\right|_{\left(x_{i}, u_{i}\right)}, \quad B^{i}=\left.\frac{\partial f}{\partial u}\right|_{\left(x_{i}, u_{i}\right)}, \\
& C^{i}=\left.\frac{\partial g}{\partial x}\right|_{\left(x_{i}, u_{i}\right)}, \quad D^{i}=\left.\frac{\partial g}{\partial u}\right|_{\left(x_{i}, u_{i}\right)}, \\
& \alpha^{i}=\left.\frac{\partial f}{\partial x}\right|_{\left(x_{i}, u_{i}\right)} x_{i}+\left.\frac{\partial f}{\partial u}\right|_{\left(x_{i}, u_{i}\right)} u_{i}-x_{i}, \\
& \gamma^{i}=\left.\frac{\partial g}{\partial x}\right|_{\left(x_{i}, u_{i}\right)} x_{i}+\left.\frac{\partial g}{\partial u}\right|_{\left(x_{i}, u_{i}\right)} u_{i}-y_{i},
\end{aligned}
$$




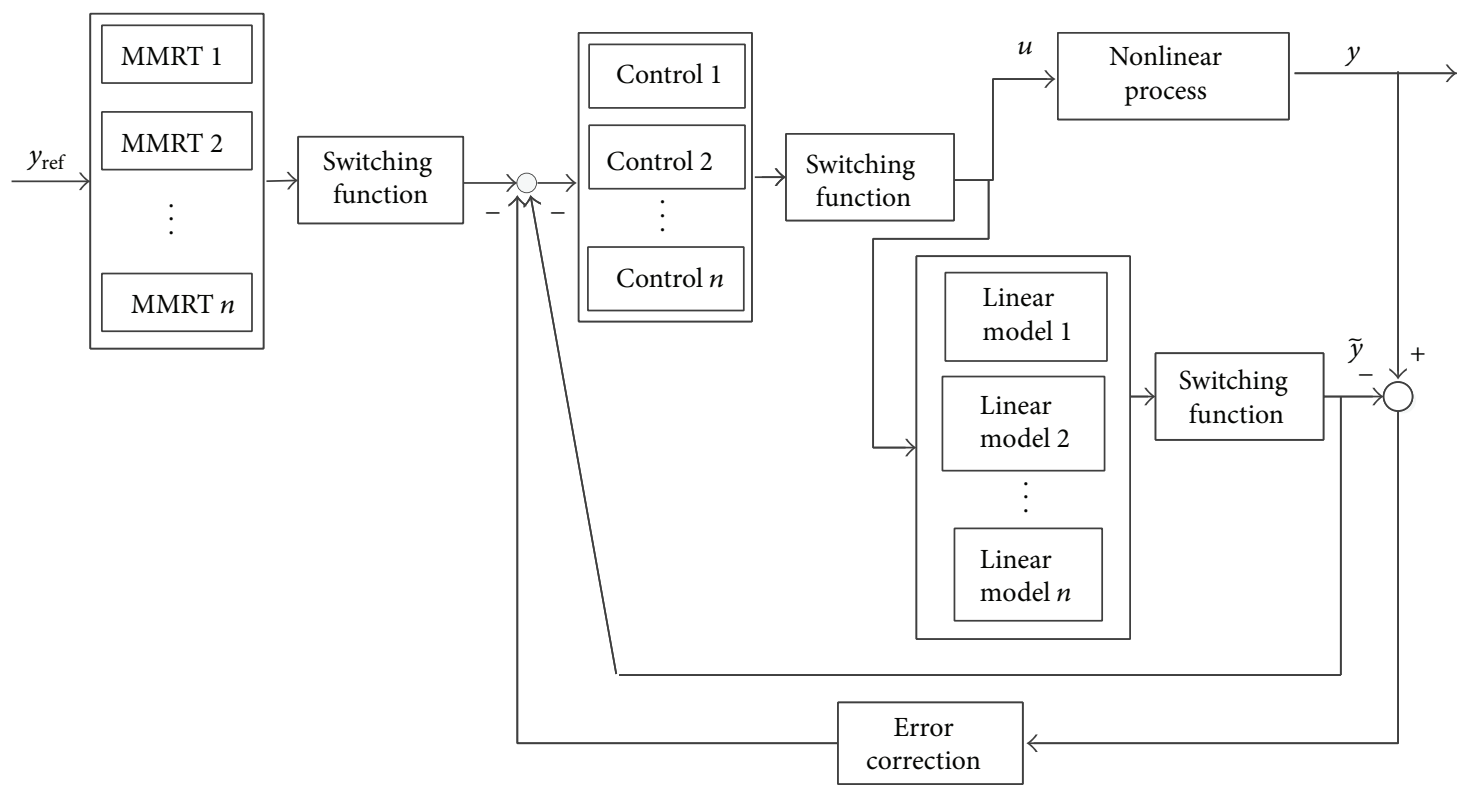

FIGURE 4: The principle frame of multiple model predictive control.

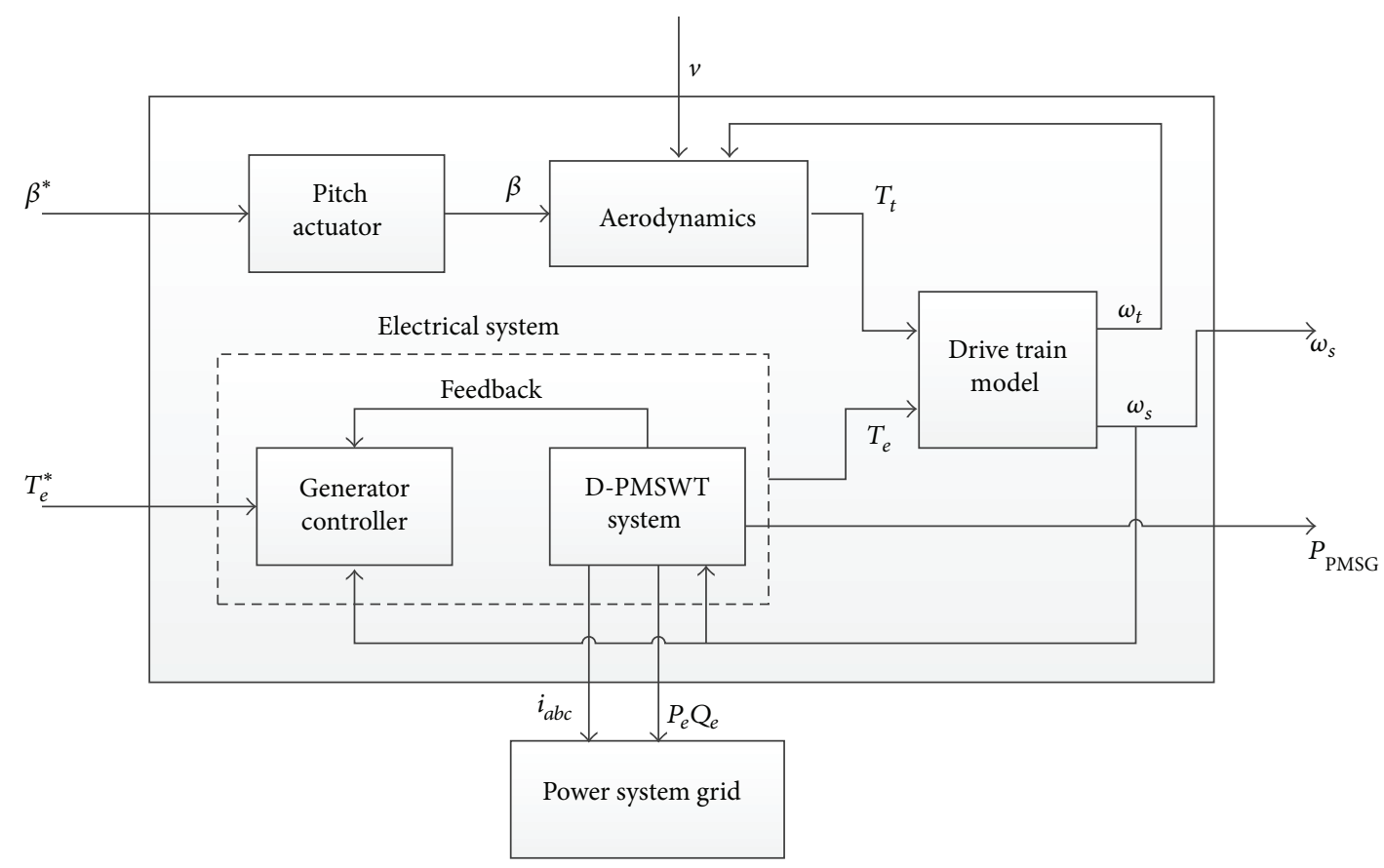

Figure 5: Model of WECS.

and $d^{i}(k)$ means measured error; the model is

$$
\begin{aligned}
& x_{d}^{i}(k+1)=\bar{A}^{i} x_{d}^{i}(k)+\bar{B}^{i} n_{d}(k), \\
& d^{i}(k)=\bar{C}^{i}(k) x_{d}^{i}(k)+\bar{D}^{i} n_{d}(k),
\end{aligned}
$$

$$
\begin{gathered}
{\left[\begin{array}{c}
x^{i}(k+1) \\
x_{d}^{i}(k+1)
\end{array}\right]=\left[\begin{array}{cc}
A^{i} & B_{d} \bar{C}^{i} \\
0 & \bar{A}^{i}
\end{array}\right]\left[\begin{array}{c}
x^{i}(k) \\
x_{d}^{i}(k)
\end{array}\right]+\left[\begin{array}{c}
B_{u}^{i} \\
0
\end{array}\right] u(k)-x_{i},} \\
y^{i}(k)=\left[\begin{array}{ll}
C^{i} & D_{d}^{i} \bar{C}^{i}
\end{array}\right]\left[\begin{array}{c}
x^{i}(k) \\
x_{d}^{i}(k)
\end{array}\right]-y_{i},
\end{gathered}
$$

Therefore, the predictive model can be obtained as

where $n_{d}(k)$ is flat noise. 


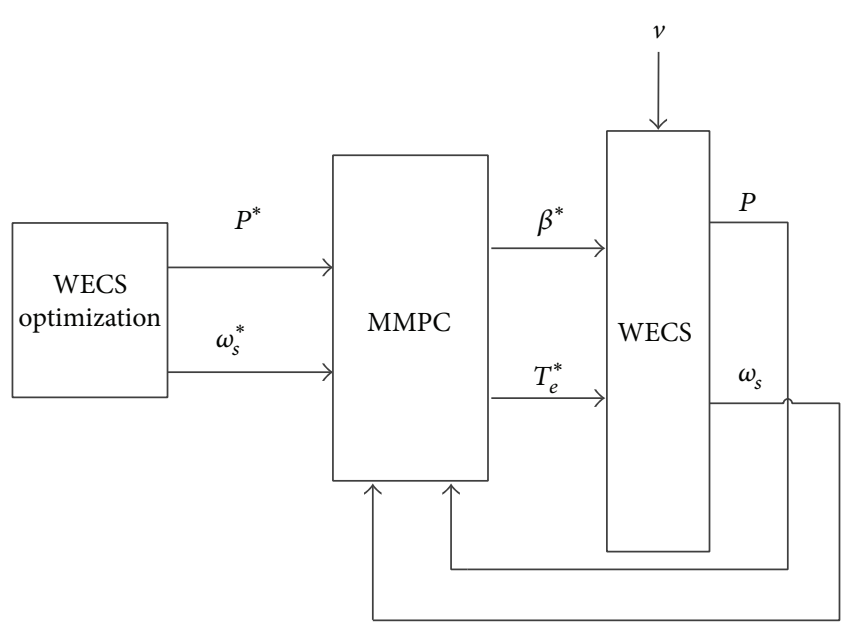

FIGURE 6: Proposed control strategy using multiple model predictive control.

where

$$
\begin{aligned}
& x^{i}(k) \stackrel{\text { def }}{=}\left[\begin{array}{llllll}
i_{d}^{i} & i_{q}^{i} & \delta \omega_{t}^{i} & \delta T_{m}^{i} & \delta T_{e}^{i} & \delta \beta^{i}
\end{array}\right]^{T}, \\
& u^{i}(k) \stackrel{\operatorname{def}}{=}\left[\begin{array}{llll}
u_{d}^{i} & u_{q}^{i} & \delta T_{e}^{* i} & \delta \beta^{* i}
\end{array}\right]^{T}, \\
& y^{i}(k) \stackrel{\text { def }}{=}\left[\begin{array}{ll}
\delta \omega_{t}^{i} & \delta P_{\mathrm{PMSG}}^{i}
\end{array}\right]^{T} .
\end{aligned}
$$

For a linear multivariable system, the predictive output of the system can be obtained through overlaying the predictive output of the single variable. Therefore, first considering predictive output $y_{l}$ caused by input $u_{j}$, the predictive value of $y_{l}$ of future $P$ moments could be obtained. The value is as follows:

$$
\tilde{y}_{l, P M}^{i}(k)=\tilde{y}_{l, P 0}^{i}(k)+A_{l, j}^{i} \Delta u_{j, M}(k),
$$

where

$$
\begin{aligned}
& \tilde{y}_{l, P M}^{i}(k)=\left[\begin{array}{c}
\tilde{y}_{l, M}^{i}(k+1 \mid k) \\
\vdots \\
\tilde{y}_{l, M}^{i}(k+P \mid k)
\end{array}\right], \\
& \tilde{y}_{l, P 0}^{i}(k)=\left[\begin{array}{c}
\tilde{y}_{l, 0}^{i}(k+1 \mid k) \\
\vdots \\
\tilde{y}_{l, 0}^{i}(k+P \mid k)
\end{array}\right], \\
& A_{l, j}^{i}=\left[\begin{array}{ccc}
a_{l j}^{i}(1) & & 0 \\
\vdots & \ddots & \\
a_{l j}^{i}(M) & \cdots & a_{l j}^{i}(1) \\
\vdots & & \vdots \\
a_{l j}^{i}(P) & \cdots & a_{l j}^{i}(P-M+1)
\end{array}\right] \text {, } \\
& \Delta u_{j, M}^{i}(k)=\left[\begin{array}{c}
\Delta u_{j}^{i}(k) \\
\vdots \\
\Delta u_{j}^{i}(k+M-1)
\end{array}\right] .
\end{aligned}
$$

If each $u_{j}$ changes $M$ times from moment $k$, then there is

$$
\tilde{y}_{l, P M}^{i}(k)=\tilde{y}_{l, P 0}^{i}(k)+\sum_{j=1}^{M} A_{l, j}^{i} \Delta u_{j, M}^{i}(k) .
$$

Here, the forecasting model of the multivariable multiple model system is shown as follows:

$$
\begin{aligned}
& \tilde{y}_{N 1}^{i}(k)=y_{N 0}^{i}(k)+\bar{A}^{i} \Delta u^{i}(k), \\
& \tilde{y}_{P M}^{i}(k)=\tilde{y}_{P 0}^{i}(k)+A^{i} \Delta u_{M}^{i}(k),
\end{aligned}
$$

where

$$
\begin{gathered}
\tilde{y}_{N 1}^{i}(k)=\left[\begin{array}{c}
\tilde{y}_{1, N 1}^{i}(k) \\
\vdots \\
\tilde{y}_{p, N 1}^{i}(k)
\end{array}\right], \quad \tilde{y}_{N 0}^{i}(k)=\left[\begin{array}{c}
\tilde{y}_{1, N 0}^{i}(k) \\
\vdots \\
\tilde{y}_{p, N 0}^{i}(k)
\end{array}\right], \\
\tilde{y}_{P M}^{i}(k)=\left[\begin{array}{c}
\tilde{y}_{1, P M}^{i}(k) \\
\vdots \\
\tilde{y}_{p, P M}^{i}(k)
\end{array}\right], \quad \tilde{y}_{P 0}^{i}(k)=\left[\begin{array}{c}
\tilde{y}_{1, P 0}^{i}(k) \\
\vdots \\
\tilde{y}_{p, P 0}^{i}(k)
\end{array}\right], \\
\bar{A}^{i}=\left[\begin{array}{ccc}
a_{11}^{i} & \cdots & a_{1 m}^{i} \\
\vdots & & \vdots \\
a_{p 1}^{i} & \cdots & a_{p m}^{i}
\end{array}\right], \\
\Delta u^{i}(k)=\left[\begin{array}{ccc}
\Delta u_{1}^{i}(k) \\
\vdots \\
\Delta u_{m}^{i}(k)
\end{array}\right],
\end{gathered}
$$

The output $y_{l}^{i}$ closely tracks expectations $y_{\Gamma}^{i}$ at future $P$ moments and imposes soft constraint on $M$ control increment, leading to performance index:

$$
\min J^{i}(k)=\left\|y_{\Gamma}^{i}(k)-\tilde{y}_{P M}^{i}(k)\right\|_{Q^{i}}^{2}+\left\|\Delta u_{M}^{i}(k)\right\|_{R^{i}}^{2},
$$

where

$$
\begin{aligned}
y_{\Gamma}^{i}(k) & =\left[\begin{array}{lll}
y_{\Gamma}^{i}(k+1) & \cdots & y_{\Gamma}^{i}(k+P)
\end{array}\right]^{T}, \\
Q^{i} & =\operatorname{diag}\left[\begin{array}{lll}
q_{1}^{i} & \cdots & q_{P}^{i}
\end{array}\right], \\
R^{i} & =\operatorname{diag}\left[\begin{array}{lll}
r_{1}^{i} & \cdots & r_{M}^{i}
\end{array}\right]
\end{aligned}
$$

subject to prediction model equations

$$
\begin{gathered}
x^{i}(k)=\tilde{x}^{i}(k \mid k), \quad x_{d}^{i}(k)=\tilde{x}_{d}^{i}(k \mid k), \\
0 \leq T_{e}^{*} \leq T_{e, \max }, \\
\beta_{\min } \leq \beta^{*}(k+j) \leq \beta_{\max }, \quad j=1,2, \ldots, N, \\
\omega_{e}^{i}(k+j) \leq \omega_{e, \max }, \quad j=1,2, \ldots, P, \\
P_{\mathrm{PMSG}}^{i}(k+j) \leq P_{\mathrm{PMSG}, \max }, \quad j=1,2, \ldots, N .
\end{gathered}
$$


The in-time control increment of the system can be obtained as follows:

$$
\begin{aligned}
\Delta u^{i}(k)= & L\left[\left(A^{i}\right)^{T} Q^{i} A^{i}+R^{i}\right]^{-1} \\
& \times\left(A^{i}\right)^{T} Q^{i}\left[y_{\Gamma}^{i}(k)-\tilde{y}_{P 0}^{i}(k)\right] .
\end{aligned}
$$

The inequality constraints of the input can be expressed as follows:

$$
\mathbb{F} \Delta u_{M}(k) \leq \mathfrak{M}
$$

Here, $\mathbb{F}$ and $\mathfrak{M}$ are known quantities.

Combined with constraints, the improvement of expression for the control function is

$$
\begin{aligned}
\Delta \widehat{u}_{M}^{i}(k)= & \Delta u_{m}^{i}(k)-\left(A^{i T} Q^{i} A^{i}+R^{i}\right)^{-1}\left(\mathbb{F}^{\prime i}\right)^{T} \\
& \times\left[\mathbb{F}^{\prime i}\left(A^{i T} Q^{i} A^{i}+R^{i}\right)^{-1}\left(\mathbb{F}^{\prime i}\right)^{T}\right]^{-1} \\
& \cdot\left[\mathbb{F}^{\prime i} \Delta u_{m}^{i}(k)-\mathfrak{M}^{\prime i}\right]
\end{aligned}
$$

where $\mathbb{F}^{\prime}$ and $\mathfrak{M}^{\prime}$ consist of elements which are unsatisfied with constraints from $\mathbb{F}$ and $\mathfrak{M}$, respectively.

Due to the existence of model mismatch, predictive output may astray form the actual value. Therefore, the feedback correction is added to the system. Comparison between actual output and predictive output results in output error

$$
e^{i}(k)=y^{i}(k)-\tilde{y}^{i}(k \mid k-1) .
$$

The error can be used to predict future output error, which supplements the prediction based on models. The predictive output of the system can be expressed as

$$
\tilde{y}_{c}^{i}(k)=\tilde{y}^{i}(k)+\mathbb{k}^{i} e^{i}(k),
$$

and $\mathbb{k}^{i}=\left[\begin{array}{llll}k_{1}^{i} & k_{2}^{i} & \cdots & k_{N}^{i}\end{array}\right]$ is correcting value.

\section{Simulation Results}

In this section, the performance of the proposed control strategy is assessed. Through the simulations, the modeling of the nonlinear wind turbine model and the designed control strategy are verified to be suitable and effective. The proposed controller has been implemented on a $6 \mathrm{KW}$ wind turbine. Table 1 shows the parameters of the simulated plant.

5.1. Partial Load with Variable-Speed Operation. Firstly, performance of the MMPC controller with the classical PI control strategy in partial load operation is compared. The simulation results are shown in Figure 7. It can be seen that the MMPC control strategy and PI controller both can effectively track the reference power to achieve maximum power point tracking according to the simulation results. However, the generator power and drive train torsional torque fluctuation were effectively reduced under the MMPC controller.
TABLE 1: Wind turbine parameter value.

\begin{tabular}{lc}
\hline Parameter & Value \\
\hline Turbine radius & $2.5 \mathrm{~m}$ \\
Rated power & $6 \mathrm{KW}$ \\
Rated voltage & $220 \mathrm{~V}$ \\
Rated torque & $220 \mathrm{~N} \cdot \mathrm{m}$ \\
Rated wind speed & $10.5 \mathrm{~m} / \mathrm{s}$ \\
Maximum power coefficient & 0.476 \\
\hline
\end{tabular}

5.2. Partial Load Operation at Near Rated Wind Speed. Secondly, performance of the MMPC controller with the classical PI control strategy in partial load operation at near rated wind speed is compared. The simulation results are shown in Figure 8. Near the rated power, both the generator power and drive train torsional torque fluctuate tempestuously and the exceeding rated power occurs when the turbine controlled by PI controller. It can be seen that MMPC controller can maintain steady power output and eliminate overshoots at near rated wind speed. It can be observed in Figure 8(f) that pitch activity in MMPC control strategy changes more frequently.

5.3. Full Load Operation. Thirdly, performance of the MMPC controller with the classical PI control strategy in full load operation is compared. The simulation results are shown in Figure 9. It can be seen that MMPC controller can maintain steady power output and reduce the power fluctuations distinctly. However, the pitch angle changes more frequently, which is shown in Figure 9(c).

\section{Conclusion}

In this paper, a new kind of modeling method and a multiple model control strategy based on model predictive control techniques were proposed to control variable-speed variablepitch direct-drive wind turbine with permanent magnet synchronous generator in both partial and full load regions. In the partial load region, the MMPC controller was designed to track maximum power point (MMP). Near the rated wind speed, the proposed controller can be used to eliminate the overshoots of power and drive train torsional torque. In addition, the fluctuation of the power and the torque was significantly reduced. In the full load region, the pitch angle was implemented to regulate the smooth power output. The proposed controller has advantages of considering the multiple model structure to deal with the nonlinearity in the system. Performance of the MMPC control strategy was compared with the PI controller. Simulation results show that MMPC controller is superior to the traditional PI control method.

\section{Conflict of Interests}

The authors declare that there is no conflict of interests regarding the publication of this paper. 

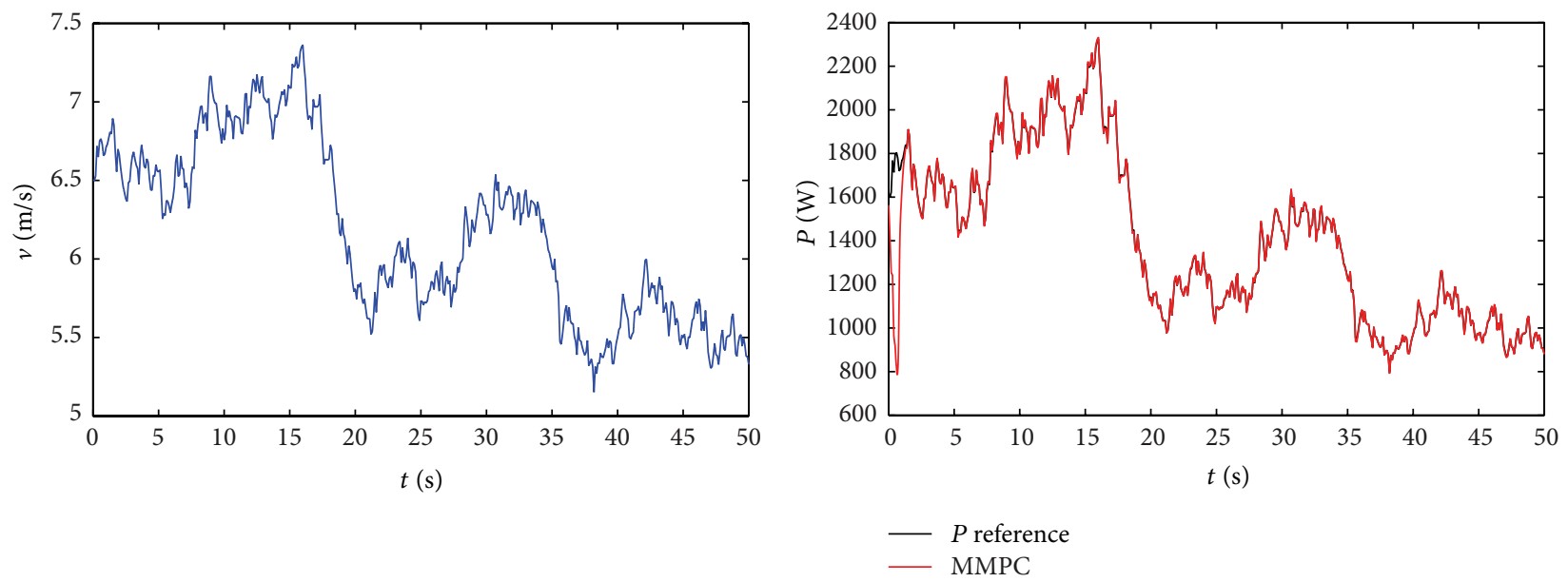

(a)

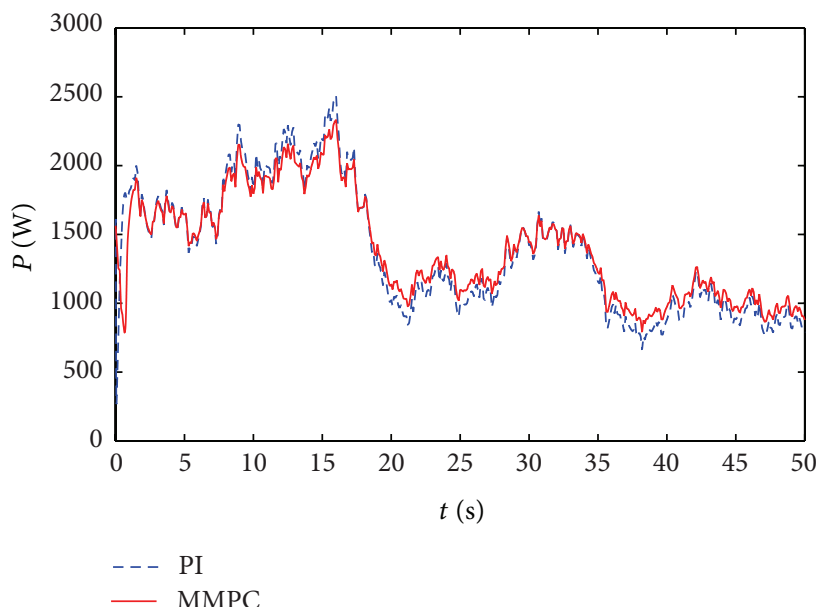

(c)

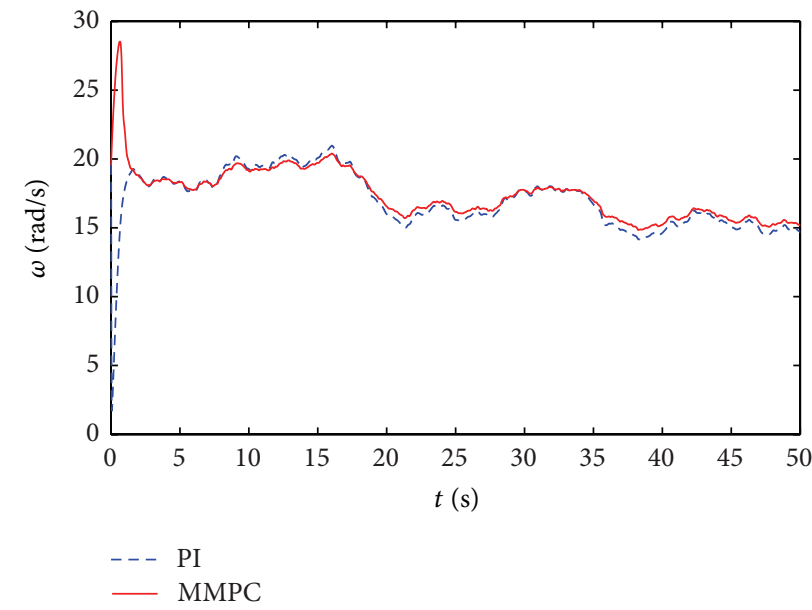

(d)

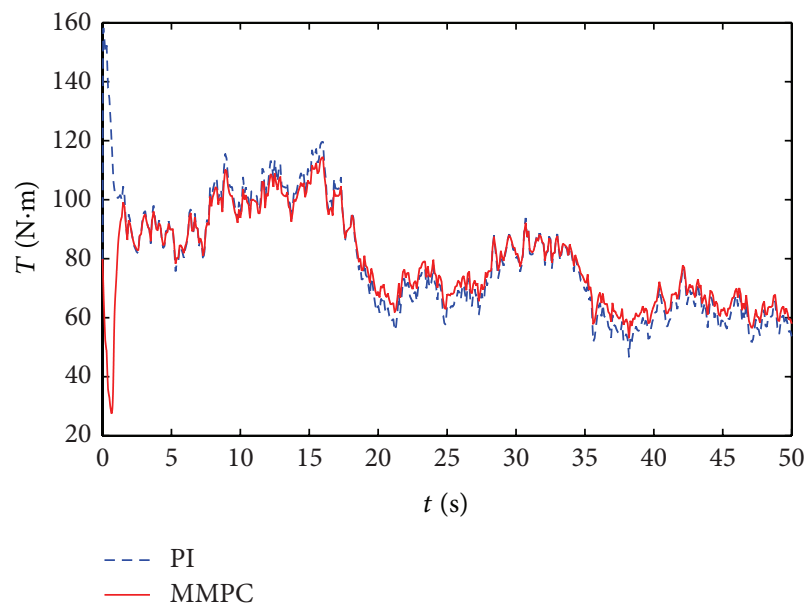

(e)

FIGURE 7: (a) Wind speed. (b) Generator power. (c) Generator power. (d) Turbine rotational speed. (e) Generator torque. 

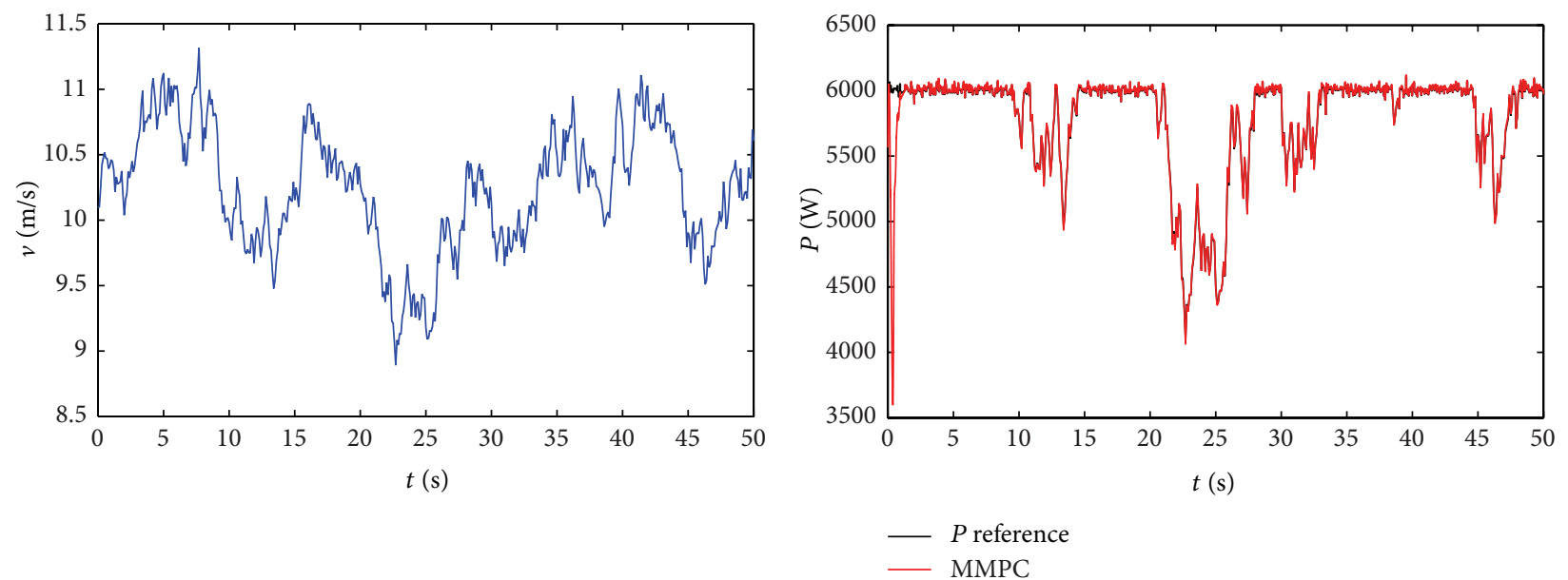

(a)
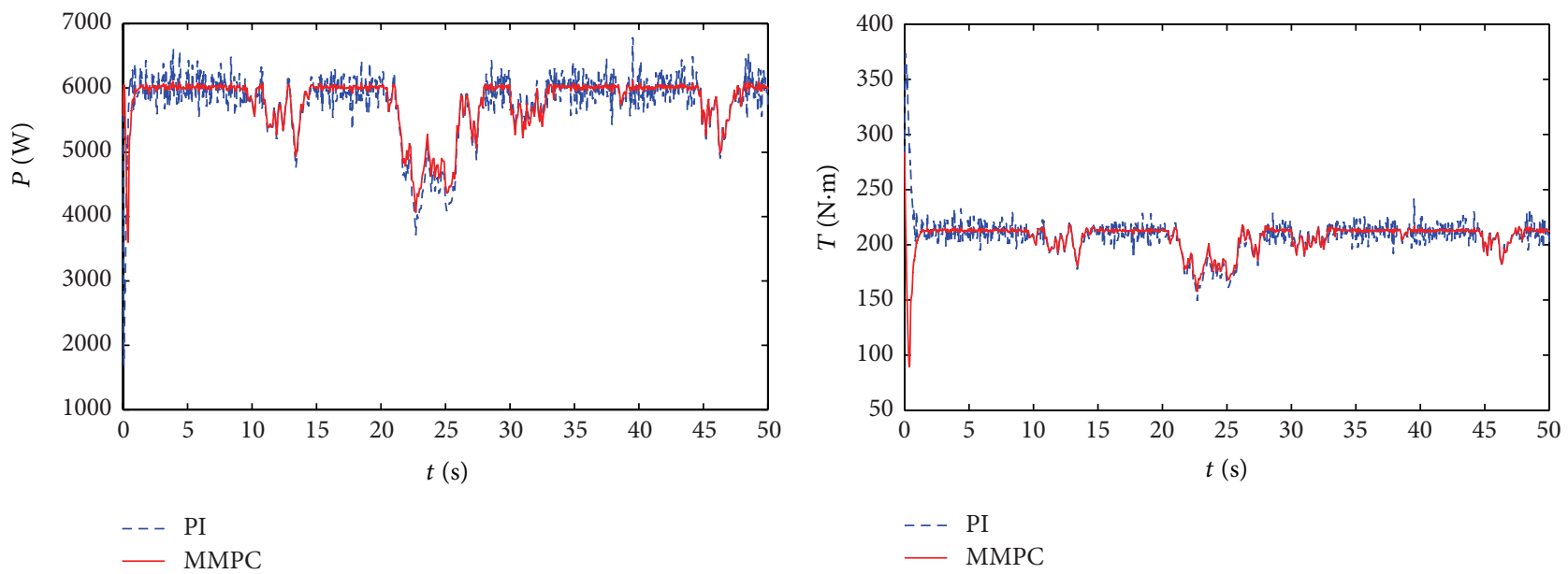

(c)

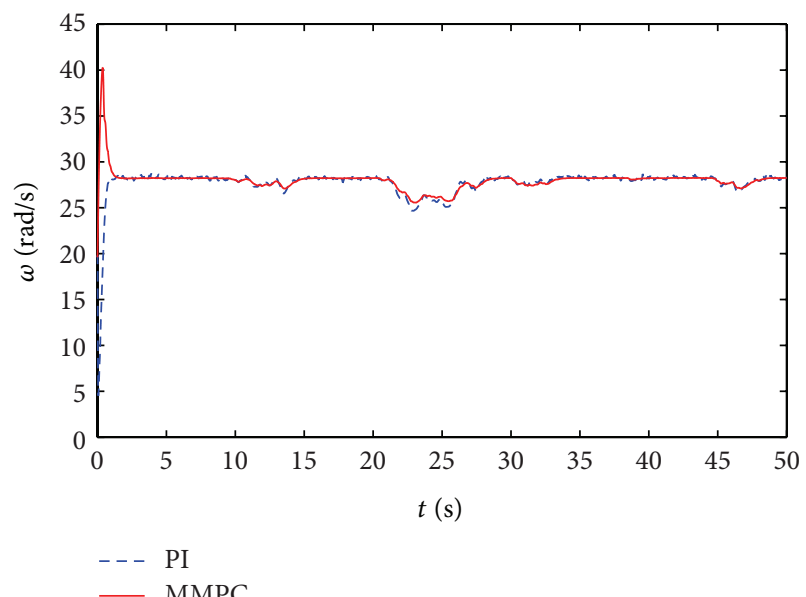

(e)

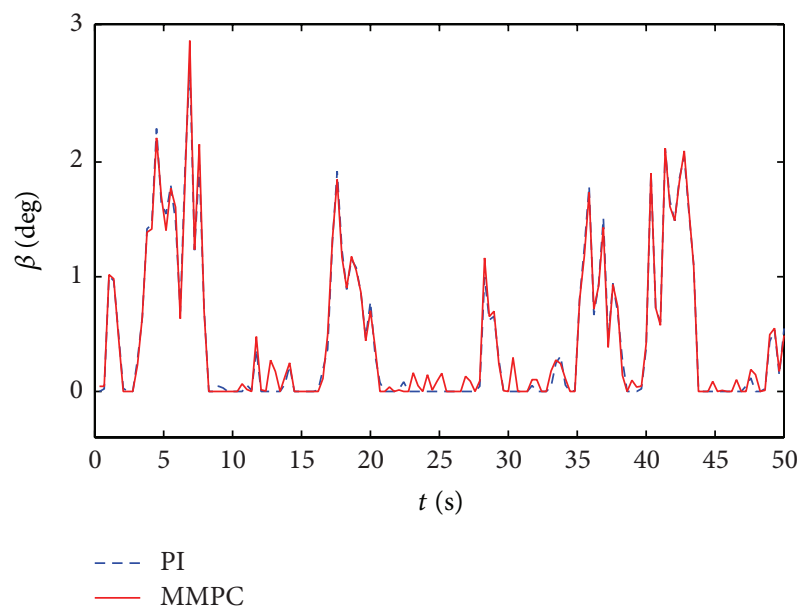

(f)

Figure 8: (a) Wind speed. (b) Generator power. (c) Generator power. (d) Generator torque. (e) Turbine rotational speed. (f) Pitch angle. 


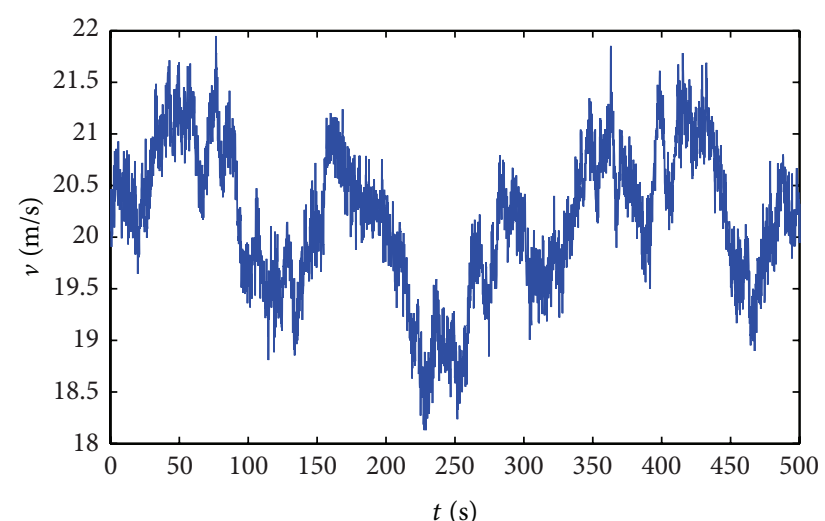

(a)

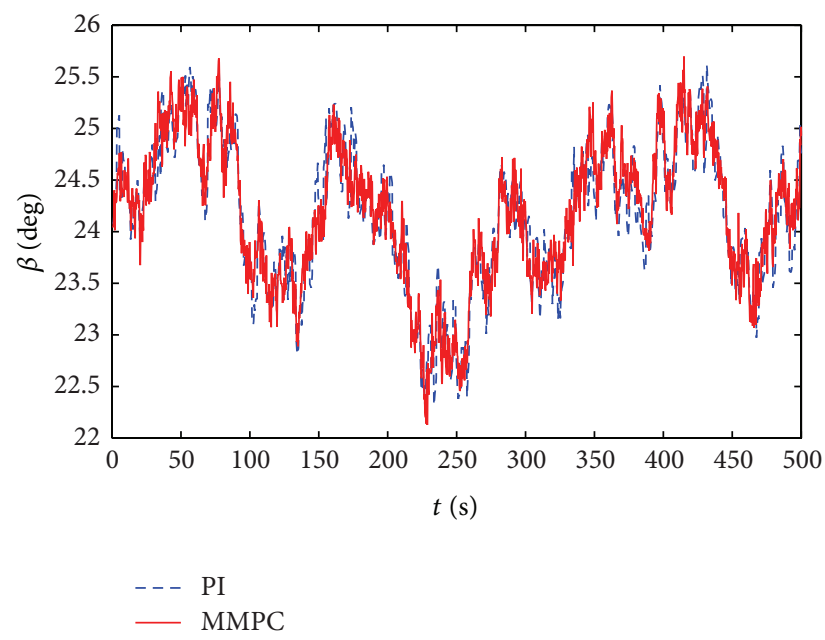

(c)

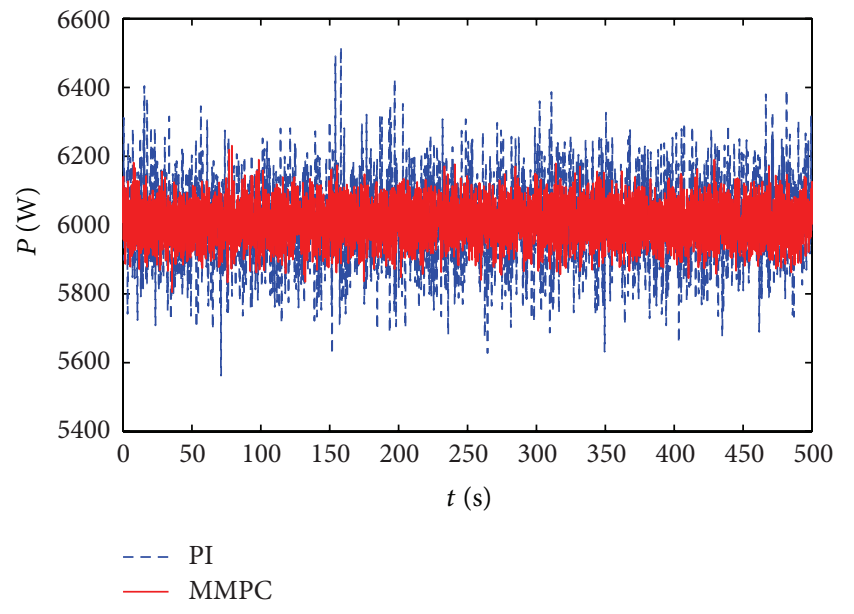

(b)

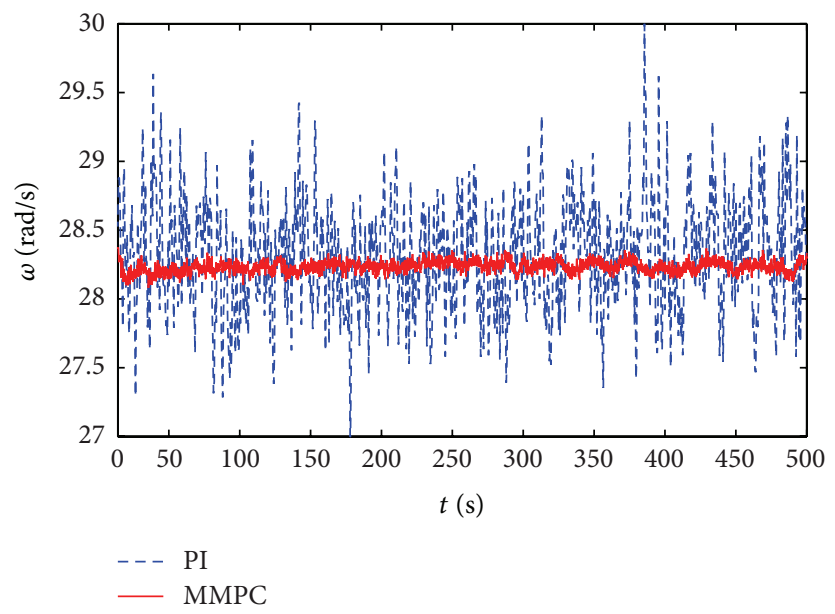

(d)

Figure 9: (a) Wind speed. (b) Generator power. (c) Pitch angle. (d) Turbine rotational speed.

\section{Acknowledgments}

This work was supported in part by Postdoctoral Research Special Project Supported by Chongqing (no. Xm2014003) and the Frontier and Applied Basic Research Project of Chongqing (no. cstc2014jcyjA1086) and the Fundamental Research Funds for the Central Universities (no.106112014CDJZR175501). The constructive comments provided by the anonymous reviewers and the editors are also greatly appreciated.

\section{References}

[1] Y. D. Song, B. Dhinakaran, and X. Y. Bao, "Variable speed control of wind turbines using nonlinear and adaptive algorithms," Journal of Wind Engineering and Industrial Aerodynamics, vol. 85, no. 3, pp. 293-308, 2000.

[2] J. H. Laks, L. Y. Pao, and A. D. Wright, "Control of wind turbines: past, present, and future," in Proceedings of the American Control Conference, pp. 2096-2103, June 2009.
[3] J. Chen, H. Wu, M. Sun, W. Jiang, L. Cai, and C. Guo, "Modeling and simulation of directly driven wind turbine with permanent magnet synchronous generator," in Proceedings of the IEEE Innovative Smart Grid Technologies-Asia (ISGT Asia '12), pp. 1-5, Tianjin, China, May 2012.

[4] M. A. Mayosky and G. I. E. Cancelo, "Direct adaptive control of wind energy conversion systems using Gaussian networks," IEEE Transactions on Neural Networks, vol. 10, no. 4, pp. 898906, 1999.

[5] W. Lin, C. Hong, T. Ou, and F. Cheng, "MRAS-based sensorless wind energy control for wind generation system using RFNN," in Proceedings of the 5th IEEE Conference on Industrial Electronics and Applications (ICIEA '10), pp. 2270-2275, 2010.

[6] F. D. Bianchi, R. J. Mantz, and C. F. Christiansen, "Gain scheduling control of variable-speed wind energy conversion systems using quasi-LPV models," Control Engineering Practice, vol. 13, no. 2, pp. 247-255, 2005.

[7] E. B. Muhando, T. Senjyu, N. Urasaki, A. Yona, H. Kinjo, and T. Funabashi, "Gain scheduling control of variable speed WTG under widely varying turbulence loading," Renewable Energy, vol. 32, no. 14, pp. 2407-2423, 2007. 
[8] C. Sloth, T. Esbensen, and J. Stoustrup, "Robust and faulttolerant linear parameter-varying control of wind turbines," Mechatronics, vol. 21, no. 4, pp. 645-659, 2011.

[9] M. Soliman, O. P. Malik, and D. T. Westwick, "Multiple model predictive control for wind turbines with doubly fed induction generators," IEEE Transactions on Sustainable Energy, vol. 2, no. 3, pp. 215-225, 2011.

[10] S. Afsharian and A. Karimpour, "Wind turbine power tracking using multiple model predictive control," in Proceedings of the 21st Iranian Conference on Electrical Engineering (ICEE '13), pp. 1-6, Mashhad, Iran, May 2013.

[11] H. D. B. A. Fernando and D. Bianchi, Wind Turbine Control Systems: Principles, Modelling and Gain Scheduling Design, Springer, London, UK, 2007.

[12] K. Z. Østergaard, J. Stoustrup, and P. Brath, "Linear parameter varying control of wind turbines covering both partial load and full load conditions," International Journal of Robust and Nonlinear Control, vol. 19, no. 1, pp. 92-116, 2009.

[13] M. Ellis, H. Durand, and P. D. Christofides, "A tutorial review of economic model predictive control methods," Journal of Process Control, vol. 24, no. 8, pp. 1156-1178, 2014.

[14] R. Lopez-Negrete, F. J. D’Amato, L. T. Biegler, and A. Kumar, "Fast nonlinear model predictive control: formulation and industrial process applications," Computers and Chemical Engineering, vol. 51, pp. 55-64, 2013.

[15] Y. G. Xi, D. W. Li, and S. Lin, "Model predictive control-current status and challenges," Acta Automatica Sinica, vol. 39, no. 3, pp. 222-236, 2013.

[16] V. R. Ravi, T. Thyagarajan, and M. M. Darshini, "A multiple model adaptive control strategy for model predictive controller for interacting non linear systems," in Proceedings of the International Conference on Process Automation, Control and Computing (PACC '11), pp. 1-8, Coimbatore, India, July 2011.

[17] H. Guolian, Z. Jinfang, L. Junjun, and Z. Jianhua, "Multiplemodel predictive control based on fuzzy adaptive weights and its application to main-steam temperature in power plant," in Proceedings of the 5th IEEE Conference on Industrial Electronics and Applications (ICIEA '10), pp. 668-673, IEEE, Taichung, Taiwan, June 2010.

[18] N. N. Nandola and D. E. Rivera, "Model-on-demand predictive control for nonlinear hybrid systems with application to adaptive behavioral interventions," in Proceedings of the 49th IEEE Conference on Decision and Control (CDC '10), pp. 6113-6118, Atlanta, Ga, USA, December 2010.

[19] B. V. Patil, S. Bhartiya, P. S. V. Nataraj, and N. N. Nandola, "Multiple-model based predictive control of nonlinear hybrid systems based on global optimization using the Bernstein polynomial approach," Journal of Process Control, vol. 22, no. 2, pp. 423-435, 2012.

[20] W. Qiao, X. Yang, and X. Gong, "Wind speed and rotor position sensorless control for direct-drive PMG wind turbines," IEEE Transactions on Industry Applications, vol. 48, no. 1, pp. 3-11, 2012. 


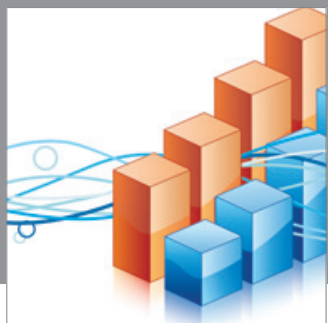

Advances in

Operations Research

mansans

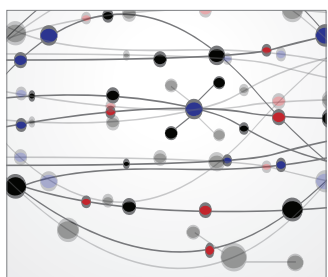

The Scientific World Journal
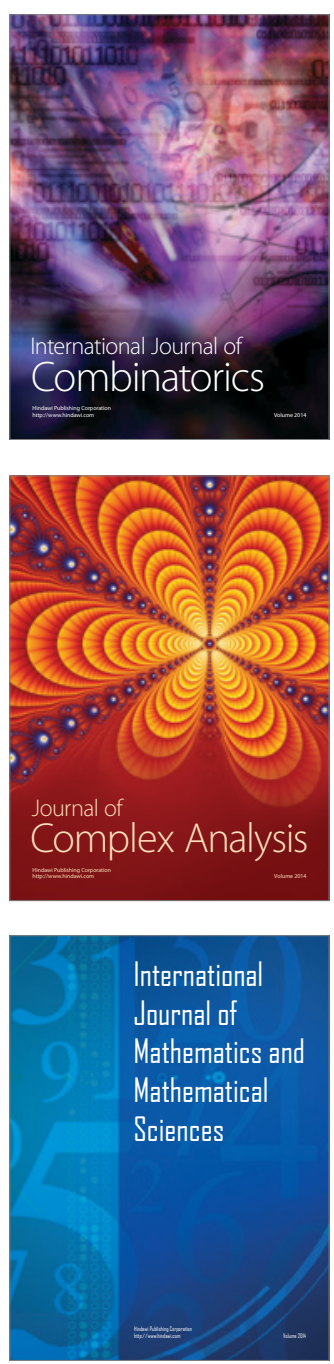
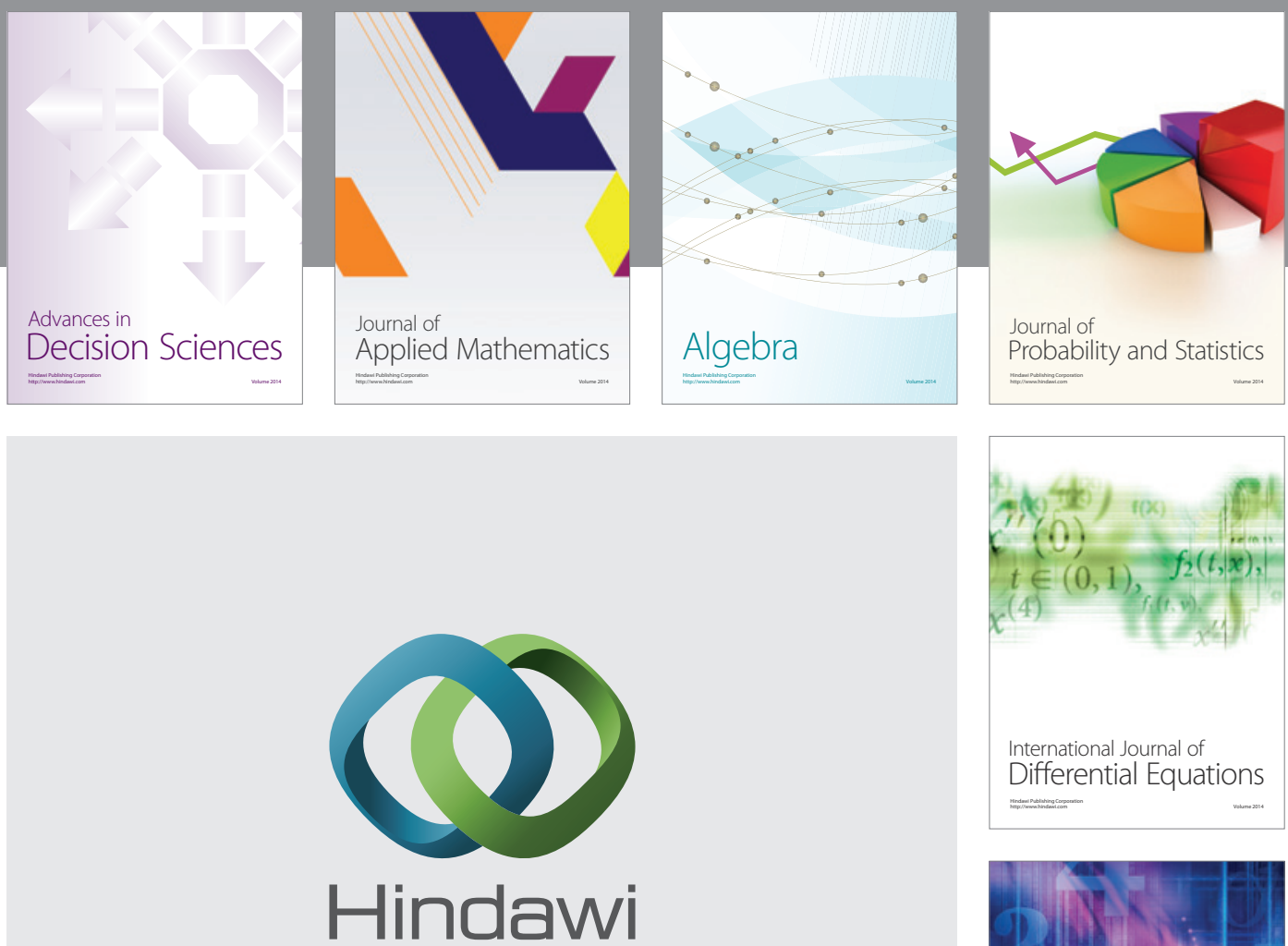

Submit your manuscripts at http://www.hindawi.com
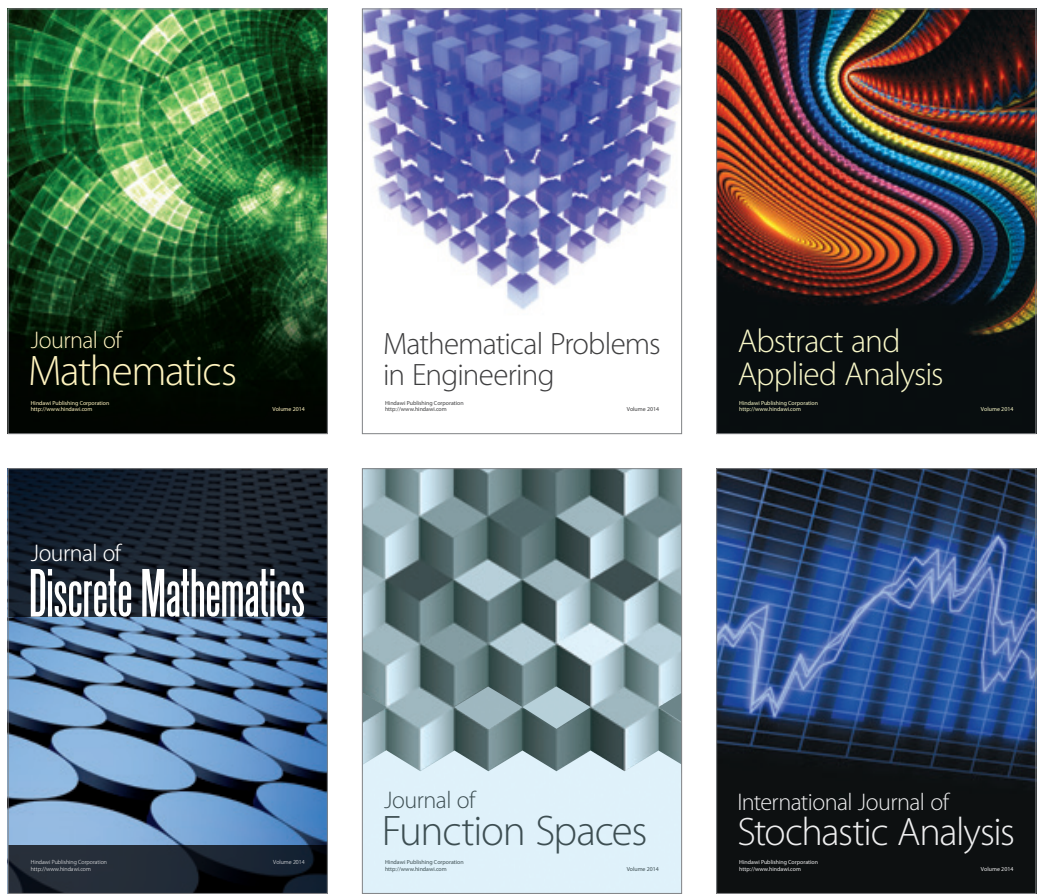

Journal of

Function Spaces

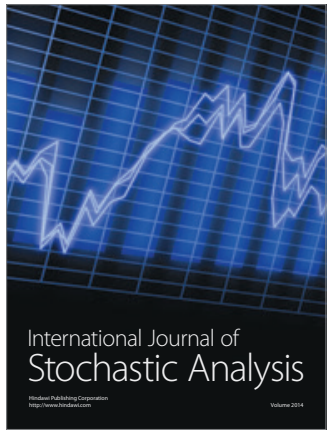

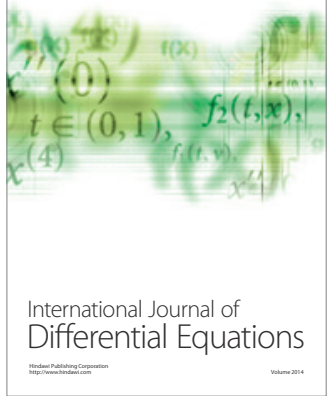
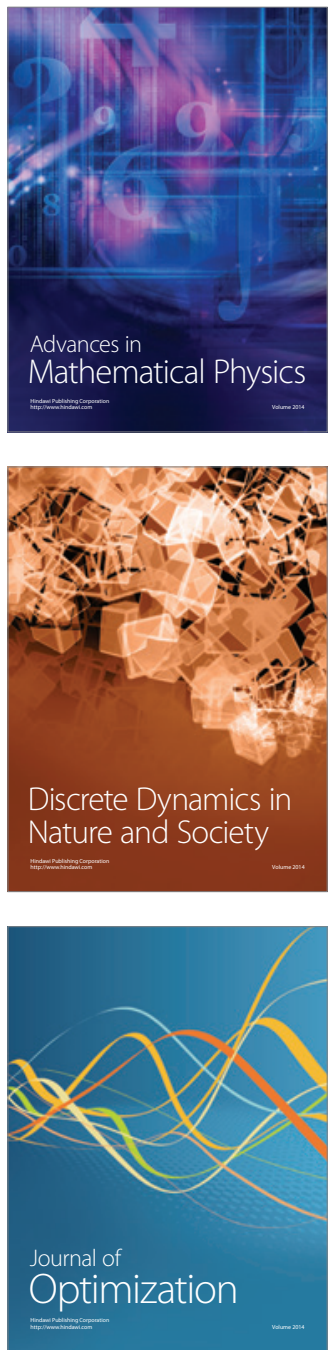